\title{
Wear Resistance of Gray Cast Iron Under High- Temperature Conditions
}

\author{
Ali A. G. Alkhafaji ${ }^{1}$ \\ \{alkhafaji.ali@stu.edu.iq ${ }^{1}$ \} \\ Al-Nasiriyah Technical Institute/ Southern Technical University, Iraq ${ }^{1}$
}

\begin{abstract}
Three different matrices Gray cast irons were produced with different carbon content and alloying elements and tested for this research purpose. A new wear test rig is designed, manufactured, and developed especially for this research. It uses to examine test materials by exposing them to a sequence of heating to $\left(600,850{ }^{\circ} \mathrm{C}\right)$ by friction with automobile brake pads in suitable condition and then air-cooled to $\left(400{ }^{\circ} \mathrm{C}\right)$. Comparisons were made between test materials in terms of weight loss after a certain number of thermal cycles, in addition to hardness number before the test as well as before and after the heat treatment. Fine grains - fully ferritic iron structure demonstrates high as-cast hardness as well as after stress relief annealing. Moreover, such material showed the best wear resistance among the test materials at $\left(600,850{ }^{\circ} \mathrm{C}\right)$. At low temperatures up to $600{ }^{\circ} \mathrm{C}$, some Gray irons have good wear resistance, but this is lost in the (to transformation) range. Hardness isn't the only criterion for high-temperature wear resistance.
\end{abstract}

Keywords: Cast iron, wear test, high temperature, wear resistance, test rig.

\section{Introduction}

Glass blow moulds, for example, must have tight dimensional tolerances and must be resistant to thermal shock, thermal conductivity, dimension stability, and wear. These moulds usually receive molten glass at around $1000 \mathrm{oC}$, which is subsequently cooled to around $500-600 \mathrm{oC}$ before being discharged. Mold materials such as cast nickel, cast iron, and tool steel are commonly used.

In high-temperature applications, grey cast iron is a popular choice. Glass blow-moulds, for example, are subjected to extremely harsh circumstances and must contain a specific set of qualities in order to be successful: Wear resistance; growth and oxidation resistance; good surface finish; surface heat checking and significant cracking (thermal shock) resistance; high thermal conductivity; and machinability [1].

Peter Elliott [2] tried answering the question: how to select alloys for high temperatures, stresses, and the presence of elements such as oxygen or sulphur. There are no significant problems up to $\left(400{ }^{\circ} \mathrm{C}\right)$, few up to $\left(750{ }^{\circ} \mathrm{C}\right)$, but the choice of successful alloys becomes somewhat limited above $\left(800{ }^{\circ} \mathrm{C}\right)$. Some alloys, have high nickel content and high nickelberyllium alloys, for example, have excellent properties but the cost is the main barrier to use these alloys in glass container blow moulds [3]. Matteis P, et al [4] concluded that the major 
damage mechanisms of cast iron are the oxidation at more than $750^{\circ} \mathrm{C}$ and thermo-mechanical fatigue of their test material which is usually used as an exhaust manifold of heavy tracks. Cast iron has a high resistance to oxidation, growth, and scaling, as well as a low inclination for deformation [7]. Scheidhauer N, et al [5] and Xiang S [6] focused on ferritic Simo cast iron which intend to use for heavy-duty engine components. They believed that aluminium and silicon increase the ( $\alpha$ to $\gamma$ transformation) temperature, $860^{\circ} \mathrm{C}$ as they mentioned. Such ferritic SiMoAl cast iron reveals excellent oxidation resistance and mechanical properties at high temperatures. High-carbon cast iron has a high heat conductivity and a low modulus of elasticity, making it resistant to thermal shock. However, it might have a coarse, open-grained surface with a poor initial finish, a predisposition to deep oxidation, and poor wear resistance as a result. Close-grained surfaces, on the other hand, can overcome these drawbacks [1].

S. Y. Buni, et al. [8] studied the effect of graphite morphology and matrix structure on the unconstrained cast iron specimens exposed to low-frequency thermal cycling. The specimens were heated inside a tubular furnace to the desired temperatures $\left(300^{\circ} \mathrm{C}, 500^{\circ} \mathrm{C}, 600^{\circ} \mathrm{C}\right.$, and $700^{\circ} \mathrm{C}$ ). The results show that au tempered ductile iron has the highest thermal cycling resistance in the above temperature range, followed by pearlitic ductile iron and compacted graphite iron, with Gray cast iron having the lowest resistance. Thermal cycling induces matrix disintegration and grain growth in all iron castings, resulting in a loss in hardness.

Wear is mechanically induced surface damage or changed surface topography because of progressive removal of material. Sometimes, wear is too big, the naked eye can see it, but with others, measuring instruments or microscopes are used to observe it. Wear as a term used in the mechanical industry indicates huge money losses due to its effect on the production facilities and products.

Junichiro Yamabe and colleagues [9] devised a new approach for evaluating thermal fatigue by replicating a high-speed braking test with a real disc brake rotor made of Gray cast iron. The quantity of graphite atoms in the microstructure increases thermal fatigue strength, according to the findings.

Cueva, et al. [10] compared the wear resistance of three different types of Gray cast iron used in car brake disc rotors (exposed to heating and cooling) to that of compacted graphite iron.

Wear, growth, thermal fatigue, and other factors can cause damage to grey cast irons in a hightemperature environment. A wear test at high temperature is required to recognise the performance of Gray cast iron used as a glass blow mould in order to acquire actual practical and dependable results. Because most commercial tribotester machines do the test at ambient temperature, the findings will be far from accurate.

Standard testing procedures will not satisfy everyone's need for wear data. Some types of wear tests have been standardised by organisations such as the American Society for Testing and Materials (ASTM), the International Organization for Standardization (ISO), and the Society of Automotive Engineers (SAE). For all types of wear, standard test procedures do not exist. Some existing standards are tailored to specific purposes, while others are more generic and based on simple geometries.

\section{Test Materials}

\subsection{Gray Cast Iron Production}


Gray iron castings' attributes are determined by their chemical composition as well as the cooling rate of the casting, which is influenced by the casting's section thickness and shape. The size, quantity, and distribution of graphite flakes, as well as the structure of the metal matrix, determine the properties of Gray irons. These, in turn, are determined by the iron's chemical composition, particularly its carbon and silicon content; as well as on manufacturing variables such as melting method, inoculation strategy, and casting cooling rate. Total carbon, silicon, and phosphorus are the three cast iron elements that have the greatest impact on strength and hardness. The Carbon Equivalent Value (CEV) is an index that incorporates the effects of these factors. In the binary $\mathrm{Fe}-\mathrm{C}$ system, the Gray iron eutectic occurs at a carbon concentration of 4.3 percent. The carbon content of the eutectic is reduced when silicon and phosphorus are present. The statement describes the influence of $\mathrm{Si}$ and $\mathrm{P}$ levels on carbon content. Hypoeutectic irons are cast irons with carbon equivalent values less than 4.3 percent, while hypereutectic irons have carbon equivalent values greater than 4.3 percent [9].

Three groups of Gray iron materials were manufactured with a different chemical composition that containing different levels of CEV, Equation (1). The results are shown in Table (1).

Carbon Equivalent Value $(C E V)=$ T.C $\%+\frac{S i \%+P \%}{3}$

To produce a certain weight $(\mathrm{Q} \mathrm{kg})$ of a destination alloy, material No.1 for example, it needs to know the furnace charge components and their weight exactly. A set of instantaneous linear equations was built and solved for this purpose. The amount of destination alloy is:

$\mathrm{Q} *$ (Chemical composition of material No.1)

$\mathrm{Q} *(3.61 \% \mathrm{C}+2.03 \% \mathrm{Si}+0.74 \% \mathrm{Mn})$

Table 1. Chemical composition of test materials.

\begin{tabular}{|c|c|c|c|c|}
\hline \multicolumn{2}{|r|}{ Materials } & Material No. 1 & Material No. 2 & Material No. 3 \\
\hline \multirow{7}{*}{ 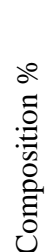 } & Carbon & 3.61 & 3.15 & 2.98 \\
\hline & Silicon & 2.03 & 2.25 & 5.117 \\
\hline & Manganese & 0.74 & 0.671 & 0.355 \\
\hline & Phosphorus & 0.09 & 0.108 & 0.11 \\
\hline & Sulphur & 0.067 & 0.062 & 0.057 \\
\hline & Molybdenum & 0.0052 & 0.006 & 0.0057 \\
\hline & Chromium & 0.021 & 0.021 & 0.022 \\
\hline \multirow{4}{*}{ 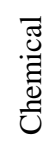 } & Nickel & 0.063 & 0.069 & 0.071 \\
\hline & Vanadium & 0.0041 & 0.0052 & 0.0034 \\
\hline & Copper & - & - & 1.329 \\
\hline & Ferrous & Balance & Balance & Balance \\
\hline \multicolumn{2}{|c|}{ Carbon Equivalent Value } & 4.317 & 3.936 & 4.722 \\
\hline
\end{tabular}

The furnace charge is:

( $\mathrm{S} \mathrm{kg}$ of Scrap $+\mathrm{X} \mathrm{kg}$ of Ferrosilicon $+\mathrm{Y} \mathrm{kg}$ of Ferromanganese $+\mathrm{Z} \mathrm{kg}$ of Graphite)

Referring to Tables (1), (2) and (3), and;

For Carbon is: $\quad 0.02503 \mathrm{~S}+0 \mathrm{X}+0.065 \mathrm{Y}+0.985 \mathrm{Z}=0.0361 \mathrm{Q}$

For Silicon: $\quad 0.01426 \mathrm{~S}+0.75 \mathrm{X}+1.2 \mathrm{Y}+0 \mathrm{Z}=0.0203 \mathrm{Q}$

For Manganese: $0.00257 \mathrm{~S}+0 \mathrm{X}+0.75 \mathrm{Y}+0 \mathrm{Z}=0.0074 \mathrm{Q}$

For Ferrous: $\quad 0.9554 \mathrm{~S}+0.2478 \mathrm{X}+0.1726 \mathrm{Y}+0 \mathrm{Z}=0.9337 \mathrm{Q}$ 
To produce the test alloys from previously prepared materials and correct alloys, a computer program was designed based upon the Gauss elimination method. The weight losses during melting and casting of each element should be added. Scrap castings were weighed by using a $(100 \mathrm{~kg})$ balance. Other raw materials were weighed by using Sartorius GM612 electronic balance with an accuracy of (0.01 gr).

Table 2. Chemical composition of alloying elements.

\begin{tabular}{|l|c|c|c|}
\hline Alloy & Ferrosilicon & Ferromanganese & Graphite \\
\hline Carbon \% & - & $6-7$ & $98-99$ \\
\hline Silicon \% & 75 & 1.2 & - \\
\hline Manganese \% & - & 75 & - \\
\hline Phosphorus \% & - & Max 0.02 & - \\
\hline Sulfur \% & - & Max 0.02 & 0.35 max \\
\hline Ferrous \% & 24.78 & 17.26 & - \\
\hline
\end{tabular}

Table 3. Scrap chemical composition before and after treated with limestone.

\begin{tabular}{|l|c|c|}
\hline Alloy & Untreated & Treated \\
\hline Carbon \% & 2.614 & 2.503 \\
\hline Silicon \% & 1.568 & 1.426 \\
\hline Manganese \% & 0.243 & 0.257 \\
\hline Phosphorus \% & 0.526 & 0.113 \\
\hline Sulphur \% & 0.103 & 0.0691 \\
\hline Molybdenum \% & 0.0063 & 0.0062 \\
\hline Chromium \% & 0.0195 & 0.02 \\
\hline Nickel \% & 0.076 & 0.069 \\
\hline Ferrous \% & Balance & Balance \\
\hline
\end{tabular}

\subsection{Heat Treatments}

The microstructure of material No. 1 and material No. 2 revealed graphite flakes embedded in ferrite and pearlite matrix. The inclusion of pearlite in the construction could cause material degradation, especially if it's employed at high temperatures. The breakdown of coupled carbon (cementite $\mathrm{Fe}_{3} \mathrm{C}$ ) in pearlite causes growth. Theoretically, graphitisation of mixed carbon (1\%) should result in an increase in the volume of (2.04 percent). The actual rate of increase is always higher [1]. When casting with a pearlite structure is used at high temperatures, particularly in the $(\alpha$ to $\gamma)$ transition temperature range, thermal cracks can form and propagate. The application of ferritic irons can prevent growth caused by pearlite breakdown. By annealing grey irons, ferritic structures can be achieved.

Deep oxidation can be accelerated by annealing above the critical temperature at which transformation occurs; however, pack annealing with graphite can impede this. The critical temperature for each test material is obtained in Table 4 using the formula below [1]:

Critical Temp. $=730+28(\%$ Si $)-25(\% M n)$

The graphite was packed into the specimens in a sealed steel box.

No. 3 Material: The as-cast microstructure was flakes of graphite in the ferritic matrix due to the high silicon content (5.117 percent $\mathrm{Si}$ ) and carbon content (2.98 percent $\mathrm{C}$ ). This structure is ordinary ferritic, and there is no room for expansion in the absence of coupled carbon. 


\section{Wear Test Rig at High-Temp}

Wear is the most common cause of cast iron deterioration when used at high temperatures. As in a glass blow mould, it alters the mould feature and fine curves on the cavity surface. Wear teste rigs at room temperature are commonly used to investigate material wear resistance.

When two substances rub against each other with a high relative velocity and axial pressure, they become heated. When steel - steel specimens rub against one other, for example - the temperature can reach $\left(1300{ }^{\circ} \mathrm{C}\right)$ under ideal conditions, while nonferrous materials can reach $\left(100^{\circ} \mathrm{C}\right)$ before melting. The friction welding process [12] and [13] make use of this phenomena. Based on the foregoing occurrence, a new pin-on-disc wear test rig is constructed in this study. The Gray cast iron specimens are examined with this equipment. Friction between a tested material and an automobile brake pad with acceptable qualities to attain the specified temperature causes high temperature.

\subsection{Basic Theory}

The test is based on the principle that heat is generated owing to friction force when a controlled contact pressure is applied perpendicular to the contact surface of two specimens with a relative sliding velocity between them. The generated heat is felt by the contacting substance as warmth. As a result, the temperature of the two specimens rises. Its size is determined by a number of factors, including:

1. relative sliding velocity.

2. The difference in axial pressure between the two specimens

3. Roughness of the surface.

4. Material characteristics (surface hardness, thermal conductivity, etc.).

5 . The coefficient of friction.

6 . The duration of the film.

A digital thermocouple or an infrared thermocouple can be used to measure and record temperature.

\subsection{The Test Rig Description}

In the absence of conventional equipment, a custom rig was devised and built specifically for these tests to match the criteria. Figure 1 depicts the unit's schematic diagram. The pad is rotated at the desired velocity through the gearbox by a $1450 \mathrm{rpm}, 7.5 \mathrm{~kW}$, three-phase electric motor. To secure the pad carrier, a lathe chuck is attached on the gearbox output shaft. A drill chuck installed in the tailstock held the test specimen in place. Through the system gearbox, a speed selector can be used to select the appropriate relative sliding velocity. 


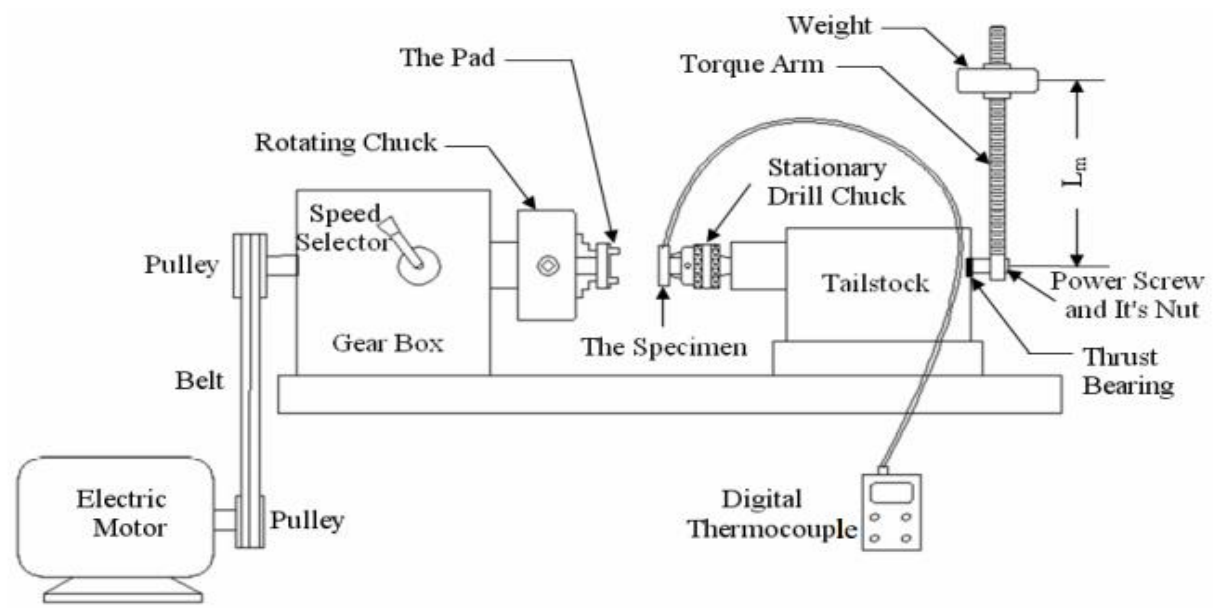

Fig 1. Schematic diagram of the high temperature wears test rig.

An axial load on a tailstock power screw can generate contact friction pressure. This pressure must be maintained in order to achieve the desired temperature. A suspended $(1 \mathrm{~kg})$ weight on a completely threaded bar is used to rotate the screw. The required torque is determined by adjusting the torque arm's distance from the spinning centre. Wear occurs in various amounts in both the specimen and the pad during the test, resulting in a loss of thickness. The pressure value is lost or reduced as a result of this. The pressure remains constant during the free fall of the hanging load. A digital thermocouple is positioned near the friction surface to monitor temperature.

\subsection{Test Specimen Preparation}

Each material's test specimen was cut from the as-cast end and machined to the dimensions (in centimetres) illustrated in Fig 2. Machining parameters were chosen to avoid specimen temperature rise. The friction surface was within $(5 \mathrm{~mm})$ from the quenched end. Annealed specimens had the same dimensions that in Fig 2 and the friction surface was $(5 \mathrm{~mm})$ from the heat-treated surface. By adjusting the torque arm length, one specimen from each material was utilised to weld a thermocouple tip and estimate the needed temperature (to set the contact pressure). At that temperature, this will remain constant for that material. Following a standard procedure, the friction face was machined, polished, and then etched for microscopic analysis. The specimen was cleaned again right before the test to remove oil, grime, fingerprints, and any other foreign substance after it was fastened into the rig's tailstock chuck. To rub the test specimen, a brake pad from a car was employed as friction material.

\subsection{Estimating the Test Temperature}

First and foremost, the rig must be free of grease, oil, dust, and any other foreign matter. The specimen and pad, on the other hand, should be clean, dry, and well-tightened before beginning the test. The motor is started up and the chuck is allowed to rotate to reach the required speed (1000 or 1400 r.p.m. to reach $600^{\circ} \mathrm{C}$ or $850^{\circ} \mathrm{C}$ respectively) for a while before making contact slightly to avoid any shock. The specimen is warm due to friction because of the relative velocity and appropriate contact pressure. A digital thermocouple was used to track temperature changes, 
as well as the time it took to achieve the cycle's maximum temperature. Increased contact pressure and temperature arise from increasing the torque arm of the free-full hanging load. The pressure is released when the required temperature $\left(600\right.$ or $\left.850^{\circ} \mathrm{C}\right)$ is attained, and the time required to reach the lowest temperature in the thermal cycle is calculated. The test is repeated several times in order to examine all parameters. The hanging weight is mounted in its position using a fully threaded torque arm and a couple of check nuts to achieve the necessary effect and hence the requisite temperature.
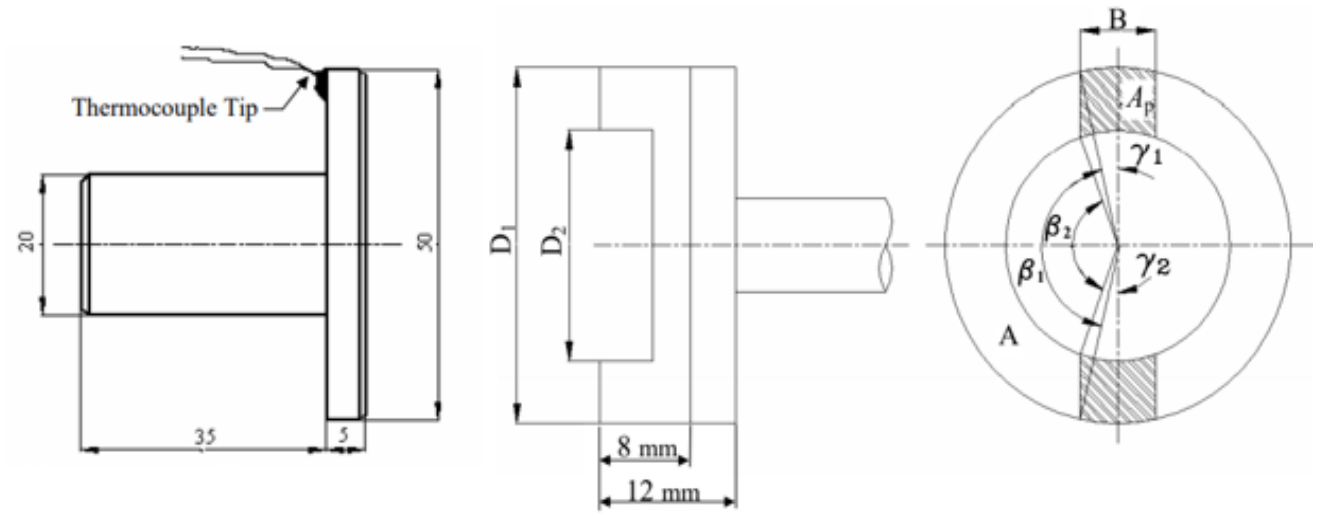

Fig 2. Wear test specimen and friction pad.

\section{Calculations}

A power screw with the following specification mounted in the tailstock is used to produce the contact pressure, Figure (3). A suspended weight ( $\mathrm{W}=10$ Newton) is mounted at a distance $\left(\mathrm{L}_{\mathrm{m}} \mathrm{mm}\right)$ on a uniform fully screwed rod. The rod's moment around the power screw axis is $\left(\mathrm{M}_{\mathrm{r}}\right.$ $=620 \mathrm{~N} . \mathrm{mm})$ and the moment of the weight is $\left(\mathrm{M}_{\mathrm{w}}\right)$. If the unit runs at (N r.p.m.), the temperature of the specimen will rise to be $\left(\mathrm{T}_{\max }{ }^{\circ} \mathrm{C}\right)$ within $\left(\mathrm{t}_{\mathrm{he}} \mathrm{sec}\right.$.). When the load is released and stops contacting, the specimen is air-cooled and takes $\left(t_{c} \sec \right)$ to reach $\left(\mathrm{T}_{\min }{ }^{\circ} \mathrm{C}\right)$.

Total torque acting on the power screw is $\left(T_{u}\right)=M_{w}+M_{r} M_{w}=W \cdot L_{m}$

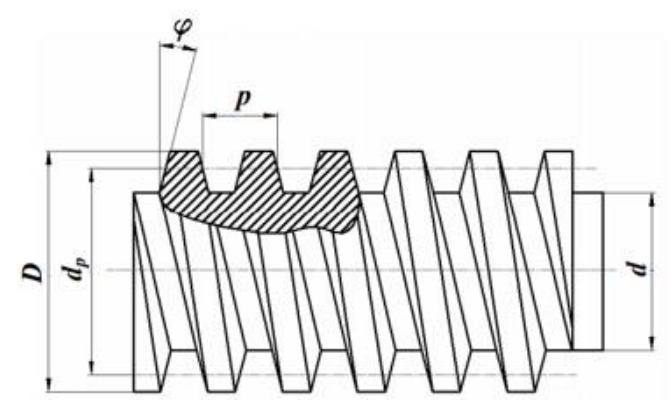

Fig 3. Single Start of Acme Thread of Power Screw.

To apply the required load to have a contact pressure between the specimen and the pad, a single-start Acme thread power screw with the following specification is used: 
- Major diameter $\mathrm{D}=26 \mathrm{~mm}$

- Minor diameter $\mathrm{d}=21 \mathrm{~mm}$

- $\quad$ Pitch $\mathrm{p}=5 \mathrm{~mm}$

- Lead $\mathrm{L}=\mathrm{p}$ for single start screw

- Pitch diameter $\mathrm{d} \mathrm{p}=23.5 \mathrm{~mm}$

- Acme teeth angle $\varphi=14.5^{\circ}$

- The material of the screw and nut is hard steel then the coefficient of friction $\mu$ is 0.15 for a static lubricated situation [14].

The relative motion between the screw and nut is too slow and can be assumed as a static case. The coefficient of friction for thrust ball bearing light series DIN 711 (Aug. 1942) symbol (51206) is 0.02 [15].

$T_{u}=T_{s u}+T_{b}=\frac{F \cdot d_{p}}{2} \cdot \frac{\left(\mu \cdot \pi \cdot d_{p}+L \cdot \cos \varphi\right)}{\left(\pi \cdot d_{p} \cdot \cos \varphi-\mu \cdot L\right)}+\mu_{b} \cdot F \cdot \frac{d_{p}}{2}$

The second term of Equation (5) can be eliminated by using a sufficient load added to the torque arm weight allowing the screw to rotate freely, then Equation (5) becomes:

$$
T_{u}=T_{s u}=\frac{F \cdot d_{p}}{2} \cdot \frac{\left(\mu \cdot \pi \cdot d_{p}+L \cdot \cos \varphi\right)}{\left(\pi \cdot d_{p} \cdot \cos \varphi-\mu \cdot L\right)}
$$

The contact pressure area $A_{p}$ can be calculated by referring to Figure (2) which has the following data: $\mathrm{D} 1=46 \mathrm{~mm}, \mathrm{D} 2=30 \mathrm{~mm}$, and $\mathrm{B}=15 \mathrm{~mm}$

$A_{p}=\frac{\pi}{4}\left(D_{1}^{2}-D_{2}^{2}\right)-2 A$

Area of segment of circle $=\frac{r^{2}}{2}(\hat{\beta}-\sin \beta)$

Then;

$$
\begin{array}{r}
A=\frac{D_{1}^{2}}{8}\left(\hat{\beta}_{1}-\sin \beta_{2}\right)-\frac{D_{2}^{2}}{8}\left(\hat{\beta}_{2}-\sin \beta_{2}\right) \\
(\hat{\beta}=\beta \text { in circular measure })
\end{array}
$$

Then;

$\hat{\beta}_{1}=\frac{\pi}{180^{\circ}} \cdot \beta_{1} \quad \& \quad \hat{\beta}_{2}=\frac{\pi}{180^{\circ}} \cdot \beta_{2}$

From Fig 2

$\beta_{1}=180-2 \gamma_{1} \quad \& \quad \beta_{2}=180-2 \gamma_{2}$

And

$\gamma_{1}=\sin ^{-1}\left(\frac{B}{D_{1}}\right) \quad \& \quad \gamma_{2}=\sin ^{-1}\left(\frac{B}{D_{2}}\right)$

Then; $A_{p}=247.078 \mathrm{~mm}^{2}$

Friction mean linear velocity $v[\mathrm{~mm} / \mathrm{sec}]$ is;

$\mathrm{v}=\frac{\pi \cdot D_{m} \cdot N}{60}$ 
$D_{m} \frac{D_{1}+D_{2}}{2}$

\subsection{Furnace Charge}

The furnace charge needed to produce the test materials shown in Table 1 from the alloying elements shown in Table 2 and pre-treated scrap with the chemical composition shown in Table 3. A computer program was built to determine the quantities. Table 5 shows the output of the program.

\subsection{Heat Treatment}

Stress relief annealing was carried out on the test materials. Brinell hardness test was carried out before and after annealing. The results as the average of five hardness numbers for each tested material are shown in Table 5.

Table 5. Furnace charge to produce $10 \mathrm{~kg}$ and Brinell hardness number of each single material

\begin{tabular}{|l|c|c|c|}
\hline \multicolumn{1}{|c|}{ Materials } & 1 & 2 & 3 \\
\hline Scrap $(\mathrm{kg})$ & 9.788 & 9.855 & 9.525 \\
\hline Ferrosilicon $(\mathrm{kg})$ & 0.09196 & 0.1229 & 0.55104 \\
\hline Ferromanganese $(\mathrm{kg})$ & 0.07474 & 0.06962 & 0.01837 \\
\hline Graphite $(\mathrm{kg})$ & 0.12982 & 0.07491 & 0.06791 \\
\hline Copper $(\mathrm{kg})$ & - & - & 0.13424 \\
\hline \multicolumn{5}{|c|}{ Brinell hardness number } \\
\hline Before annealing & 260 & 240 & 319 \\
\hline After annealing & 145 & 141 & 328 \\
\hline
\end{tabular}

The matrix structures of No. 1 and No. 2 are pearlitic and ferritic, respectively, as shown in Fig 4. Pearlite has a higher hardness than ferrite. After annealing, the microstructure changes from pearlite and ferrite to totally ferritic, resulting in a significant reduction in hardness (Fig 4).

Among the test materials in this study, Material No. 3 had the greatest as-cast hardness number. The presence of copper (1.329 percent $\mathrm{Cu}$ ) and a high silicon content (5.117 percent $\mathrm{Si}$ ) cause hardness to increase, as indicated in Table 5. They make ferrite stronger and give it a fine grain size [1]. Because there is a lot of fine-grained structure, there is a lot of thermal conductivity. The structure becomes totally ferritic with a high amount of graphite flakes when the silicon content is high, which reduces crack propagation and boosts heat conductivity [9]. Because of its ferritic as-cast structure, Material No. 3 offers outstanding growth resistance. High silicon content combined with copper presence will limit deep oxidation growth [1]. Because the silicon will be resolved and distributed in ferrite, the hardness value of stress relief casting will be larger than before, resulting in an increase in hardness by reinforcing the mechanism. 


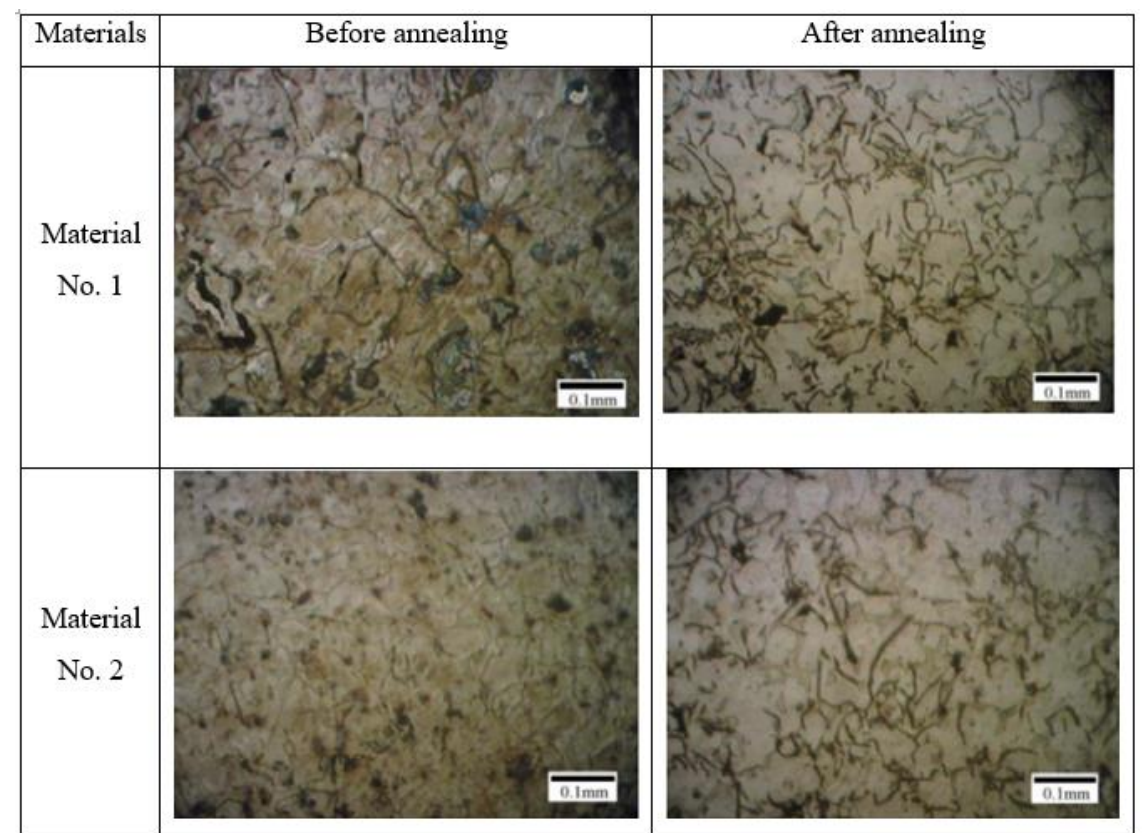

Fig 4. Microstructure of material No. 1 and No. 2 before and after annealing.

\section{High-Temperature Wear Test}

\subsection{Wear Test at $600^{\circ} \mathrm{C}$}

Table 6 shows the residual characteristics from the first wear test, which was conducted at $\left(\mathrm{T}_{\max }\right.$ $\left.=600{ }^{\circ} \mathrm{C}\right)$ and $\left(\mathrm{T}_{\min }=400{ }^{\circ} \mathrm{C}\right)$. Three specimens of each test material were tested to ensure that the results were repeatable.

Table 6. Wear test parameters at $600^{\circ} \mathrm{C}$.

\begin{tabular}{|l|l|}
\hline$T_{\max }\left({ }^{\circ} \mathrm{C}\right)$ & 600 \\
\hline$T_{\min }\left({ }^{\circ} \mathrm{C}\right)$ & 400 \\
\hline $\mathrm{T}_{\mathrm{h}}(\mathrm{sec})$ & 50 \\
\hline Soaking time $(\mathrm{sec})$ & 10 \\
\hline $\mathrm{t}_{\mathrm{c}}(\mathrm{sec})$ & 85 \\
\hline $\mathrm{N}($ r.p.m. $)$ & 1000 \\
\hline $\mathrm{L}_{\mathrm{m}}(\mathrm{mm})$ & 176 \\
\hline $\mathrm{T}_{\mathrm{u}}(\mathrm{N} \cdot \mathrm{mm})$ & 2346.56 \\
\hline $\mathrm{P}(\mathrm{MPa})$ & 3.592 \\
\hline$v(\mathrm{~m} / \mathrm{sec})$ & 1.9897 \\
\hline
\end{tabular}

As a consequence of the test, the wear in specimens was assessed as a cumulative mass loss after each ( 25 thermal cycles). Figure 5 shows the average results for each test material area. 
Material No. 3 has the highest hardness number among the test materials, as shown in Table 5, and it has the lowest weight loss due to its chemical composition and microstructure; for example, a high amount of graphite flakes with silicon - strengthen ferrite as shown in Fig 6.

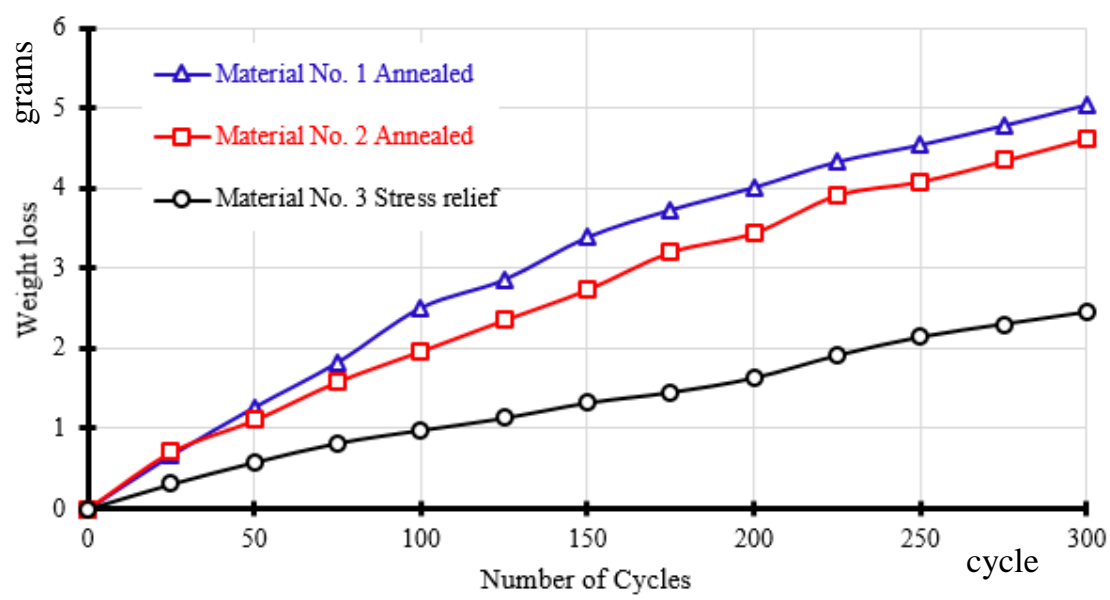

Fig 5. Weight losses as a function of several thermal cycles at $600^{\circ} \mathrm{C}$.
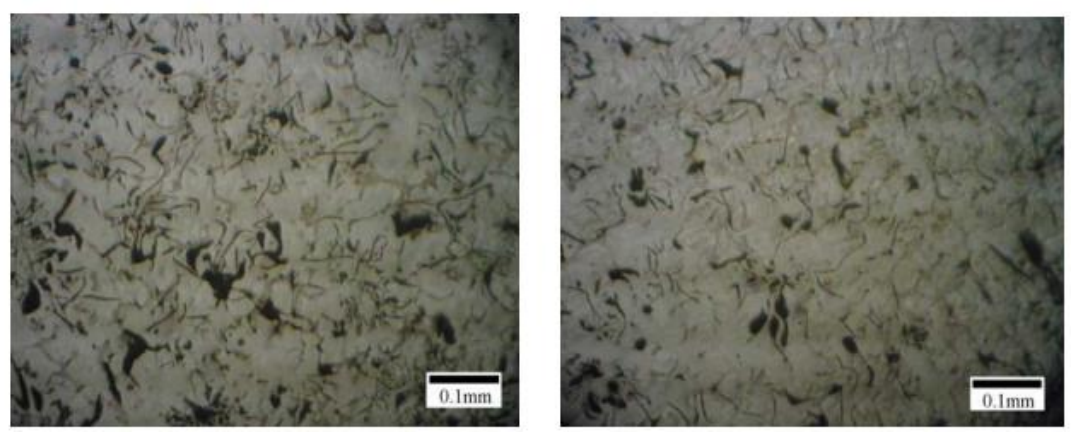

Fig 6. Microstructure of material No. 3 .

\subsection{Wear Test at $850^{\circ} \mathrm{C}$}

A second set of testing was performed at temperatures of $\left(\operatorname{Tmax}=850{ }^{\circ} \mathrm{C}\right)$ and $\left(\mathrm{Tmin}=400{ }^{\circ} \mathrm{C}\right)$, with the remaining test parameters indicated in Table 7 . Three specimens of each test material were tested to ensure that the results were consistent. The cumulative mass loss after each test was used to determine how worn the specimens were (10 cycles). Figure 6 shows the average of the results for each test item. As indicated in Table 5, Material No. 3 has the greatest hardness number among the test materials and gives the least weight loss up to $850^{\circ} \mathrm{C}$. Figure 7 demonstrates that of the test materials, substance No. 2 has the greatest weight reduction, followed by material No.1. Meanwhile, for its chemical composition and microstructure, material No. 3 has the lowest weight loss each cycle of all test materials; for example, a high quantity of graphite flakes with silicon - reinforce ferrite as shown in Fig 6. Material No.1 and 
material No. 2 were evaluated in the (to transition temperature range), which resulted in both pearlites break down and matrix oxidation, as indicated in Table 8. Growth will produce rapid fracture initiation and propagation, and graphite flakes will dislocate small sections of the surface.

Table 8 shows that Material No.3 was tested at a temperature below its critical temperature. The microstructure of material No.3 is ferritic, as seen in Fig 6. There is no growth in the absence of cementite and pearlite, implying that combined carbon is broken down. As a result of the high silicon and copper content, matrix oxidation and growth are inhibited.

Table 7. Wear test parameters at $850^{\circ} \mathrm{C}$.

\begin{tabular}{|l|l|}
\hline $\mathrm{T}_{\max }\left({ }^{\circ} \mathrm{C}\right)$ & 850 \\
\hline $\mathrm{T}_{\min }\left({ }^{\circ} \mathrm{C}\right)$ & 400 \\
\hline $\mathrm{T}_{\mathrm{h}}(\mathrm{sec})$ & 110 \\
\hline Soaking time $(\mathrm{sec})$ & 10 \\
\hline $\mathrm{t}_{\mathrm{c}}(\mathrm{sec})$ & 175 \\
\hline $\mathrm{N}(\mathrm{r} . \mathrm{p} . \mathrm{m})$. & 1400 \\
\hline $\mathrm{L}_{\mathrm{m}}(\mathrm{mm})$ & 185 \\
\hline $\mathrm{T}_{\mathrm{u}}(\mathrm{N} . \mathrm{mm})$ & 2434.85 \\
\hline $\mathrm{P}(\mathrm{MPa})$ & 3.727 \\
\hline$v(\mathrm{~m} / \mathrm{sec})$ & 2.7855 \\
\hline
\end{tabular}

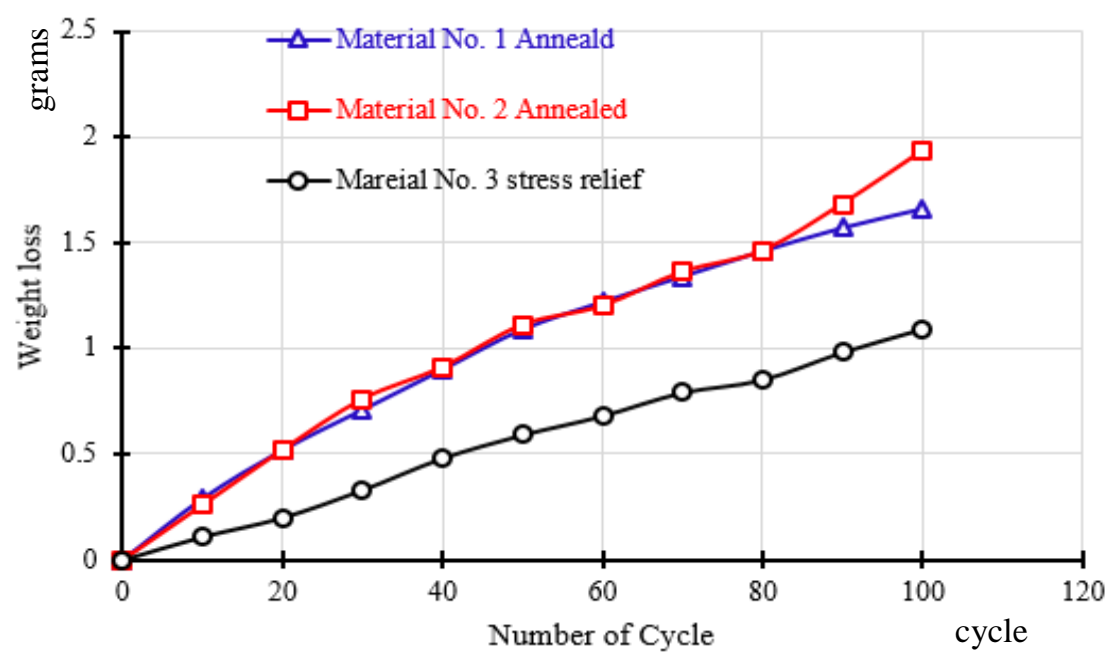

Fig 7. Weight losses as a function of the number of thermal cycles at $850{ }^{\circ} \mathrm{C}$.

Table 8. Critical Temperature for the test materials.

\begin{tabular}{|l|c|}
\hline Materials & Critical Temperature ${ }^{\circ} \mathrm{C}$ \\
\hline Material No. 1 & 765.35 \\
\hline Material No. 2 & 776.225 \\
\hline Material No.3 & 864.401 \\
\hline Critical Temperature $=730+28(\% \mathrm{Si})-25(\% \mathrm{Mn})[1]$ \\
\hline
\end{tabular}




\section{Conclusions}

The following are the key results reached as a result of this research:

1. The wear tests reveal that hardness is not the essential criterion for abrasive wear resistance, particularly at high temperatures.

2. For the same chemical composition, pearlitic structure material has higher hardness at room temperature than ferritic, and it has superior wear resistance than ferritic at high temperatures prior to transformation; for example, up to roughly $600 \mathrm{oC}$ as well as at room temperature.

3. Ferritic Gray cast iron has a stronger wear resistance than pearlitic Gray cast iron in the (to transformation) temperature range due to its resistance to pearlite growth, free cementite break down, and deep oxidation.

4. Some grey cast iron, such as pearlite structure, mottled structure, and white cast iron, has great wear resistance at low temperatures, but it is weak at higher temperatures, particularly in the ( $\alpha$ to $\gamma$ transformation) temperature range. As a result, if Gray cast iron is meant to be utilised near the critical temperature, a wear test at ambient temperature will never give a good indication of material wear resistance.

\section{Acknowledgments}

The author wishes to acknowledge Al-Nasiriyah Technical Institute - Southern Technical University, Iraq as the test rig was fabricated and the practical tests were accomplished at its workshops.

\section{References}

[1] H. T. Angus. Cast Iron: Physical and Engineering properties. Second edition. Butterworths; reprinted, 1978.

[2] CORROSION/2000 (NACE International 55th Annual Conference and Exhibition: Peter Elliott. Choose Materials for High - Temperature Environments, Based on a paper presented at CORROSION/2000 (NACE International 55th Annual Conference and Exhibition), Mar. 26 - 31, 2000, Orlando, FL, USA.

[3] OMCO. Mould data sheet. I - 12 (September 1975).

[4] Journal article: Matteis P, Scavino G, Castello A, Firrao D. High temperature fatigue properties of a Si-Mo ductile cast iron. Procedia Materials Science. 2014 Jan 1;3:2154-9.

[5] OMCO. Mould data sheet. I - 6 (June 1975).

[6] Scheidhauer N, Dommaschk C, Wolf G. Oxidation Resistant Cast Iron for High Temperature Application. In Materials Science Forum 2018 (Vol. 925, pp. 393-399). Trans Tech Publications Ltd.

[7] Xiang S. High-temperature corrosion-fatigue of cast alloys for exhaust manifolds (Doctoral dissertation, KTH Royal Institute of Technology).

[8] OMCO. Mould data sheet. I - 6 (June 1975).

[9] S. Y. Buni, N. Raman and S. Seshan. The Role of Graphite Morphology and Matrix Structure on Low Frequency Thermal Cycling of Cast Irons. Sadhana, India. February 2004; Vol. 29; Part 1: 117 $-127$.

[10] Junichiro Yamabe, Masami Takagi and Toshiharu Matsui. Development of Disc Brake Rotors for Heavy - and Medium - Duty Trucks with High Thermal Fatigue Strength. 2003; Technical papers; Technical Review; No. 15.

[11] G. Cueva, A. Sinatora, W. L. Guesser and A. P. Tschiptschin. Case Study, Wear Resistance of Cast Irons Used in Brake Disc Rotors, Wear; 255(2003): 1256 - 1260.

[12] John R. Brown. Foseco Ferrous Foundryman's Handbook. Oxford: Butterworth-Heinemann, Foseco International Ltd;2000.

[13] R. F. Tylecote. Friction Welding, The solid phase welding of metals. 1968; pp. 226-257, 1968. 
[14] F. D. Duffin and A. S. Bahrani. The mechanics of friction welding mild steel. Metal Construction. 1976; Vol. 8: No. 6.

[15] Robert L. Norton. Machine Design an Integrated Approach. Prentice-Hall. Inc.; 1998. pp. 894 - 906

[16] Gustav Niemann. Machine Elements Design and calculation in mechanical engineering. Berlin: Springer - Verlag; 1978. Vol. 1.

[17] Kurt Gieck. Engineering Formulas. Fifth American edition. USA: McGraw-Hill, Inc. 1986. 